\title{
Martial Art Augmented Reality Book (Arbook) Sebagai Media Pembelajaran Seni Beladiri Nusantara Pencak Silat
}

\author{
Adi Sucipto $^{[1]^{*}}$, Qadli Jafar Adrian ${ }^{[2]}$, M. Agie Kencono ${ }^{[3]}$ \\ Fakultas Teknik dan Ilmu Komputer Universitas Teknokrat Indonesia ${ }^{[1], ~[2], ~[3] ~}$ \\ Jl. H.ZA Pagaralam, No 9-11, Labuhanratu, Bandarlampung \\ adi.sucipto@teknokrat.ac.id ${ }^{[1]}$, qadhliadrian@ @teknokrat.ac.id ${ }^{[2]}$, agiekencono@ gmail.com ${ }^{[3]}$
}

\begin{abstract}
Pencak silat is one of the archipelago cultures that must be preserved. Many people want to learn silat. Fighters need a good memory in practicing, to remember every silat movement. This must be done repeatedly to understand. For independent study, the only media available are manual books and no teaching aids. This causes the fighter to experience difficulties. Based on these problems, a medium is needed as a prop that can help fighters remember silat movements. To solve this problem, this research will make a learning media using augmented realitybased silat movement guide book (ARBook). This learning media serves as a guide to basic silat movements in the form of Androidbased 3D animation visualization, with the aim of being a martial arts props. This makes this method better than the conventional manual method. Based on the results of alpha testing using a black box. So from these data, it can be seen that the 3D AR pencak silat motion application runs and in accordance with the specified functionality are included in the feasible category. In Beta testing that uses the acceptance method, $86 \%$ of respondents agree that the AR 3D Silat Motion Application is very useful, then $87 \%$ of respondents agree that it is easy to use, then $84 \%$ of respondents agree that the animated content is presented, and $79 \%$ of respondents are interested in using the Motion Application AR 3D Silat. Suppose calculated to have an average value of $84 \%$. So it can be concluded that the value of $84 \%$ is included in the "Very Appropriate" category. Broadly speaking, Alpha and Beta testing shows that this application is considered very feasible and usable.
\end{abstract}

Keywords-Application, Pencak Silat, Augmented reality, 3D, Android.

Abstrak- Pencak silat merupakan salah satu budaya nusantara yang harus dilestarikan. Banyak masyarakat yang ingin belajar silat. Para pesilat memerlukan ingatan yang baik dalam berlatih, untuk mengingat tiap gerakan silat. Hal tersebut harus dilakukan berulang-ulang agar paham. Untuk belajar mandiri, media yang ada hanya buku manual dan tidak ada alat peraga. Hal tersebut menyebabkan pesilat akan mengalami kesulitan. Berdasarkan permasalahan tersebut, maka diperlukan sebuah media sebagai alat peraga yang dapat membantu pesilat dalam mengingat gerakan silat. Untuk mengatasi permasalahan tersebut maka dalam penelitian ini akan membuat sebuah media pembelajaran dengan menggunakan buku panduan gerakan silat berbasis augmented reality (ARBook). Media pembelajaran ini sebagai panduan gerak dasar silat dalam bentuk visualisasi animasi 3D berbasis android, dengan tujuan sebagai alat peraga silat. Hal tersebut membuat metode ini akan lebih baik dari metode buku manual yang konvesional. Berdasarkan hasil pengujian alpha dengan menggunakan black box. Maka dari data tersebut dapat diketahui bahwa aplikasi gerak pencak silat 3D AR berjalan dan sesuai dengan fungsionalitas yang ditetapkan termasuk dalam kategori layak. Pada pengujian Beta yang menggunakan metode penerimaan, $86 \%$ responden setuju bahwa Aplikasi Gerak Silat AR 3D sangat bermanfaat, kemudian $87 \%$ responden setuju bahwa mudah digunakan, selanjutnya $84 \%$ responden setuju sudah sesuai konten animasi yang disajikan, dan 79\% responden tertarik menggunakan Aplikasi Gerak Silat AR 3D. Jika dihitung memiliki nilai rata-rata $84 \%$. Maka dapat disimpulkan nilai $84 \%$ termasuk dalam kategori "Sangat Layak". Secara garis besar pengujian Alfa dan Beta menunjukkan aplikasi ini dinilai sangat layak dan dapat digunakan.

Kata Kunci-Aplikasi, Pencak Silat, Augmented reality, 3D, Android.

\section{PENDAHULUAN}

Saat ini bela diri telah banyak di pelajari dan berkembang di bumi nusantara ini, baik dari beladiri aliran luar negeri sampai ke aliran lokal. Salah satu peninggalan budaya bangsa nenek moyang Indonesia adalah Pencak Silat. Pusat ilmu beladiri tradisional pencak silat adalah Indonesia, sehingga budaya tersebut perlu dilestarikan, dibina, dan dikembangkan [1]. Studi kasus penelitian ini dilakukan di Perguruan Pencak Silat (PPS) Betako Merpati Putih. Salah satu perguruan pencak silat bela diri Tangan Kosong yang merupakan aset budaya bangsa adalah PPS Betako Merpati Putih (MP). Pada sekitar tahun 1550-an mulai terbentuk aliran jenis beladiri ini dan perlu dilestarikan serta dikembangkan selaras dengan perkembangan ilmu pengetahuan serta teknologi saat ini [2].

Dalam kehidupan sehari-hari augmented reality (AR) sudah mulai mendominasi pasar dunia. Salah satu dari kegunaan AR adalah sebagai sarana dalam bisnis, yaitu penyampaian informasi produk yang ditawarkan kepada konsumen, dapat digunakan media edukasi, game dan lain sebagainya. Augmented reality adalah inovasi bidang multimedia dan image processing yang sedang berkembang. Mengangkat sebuah benda yang sebelumnya datar (dua dimensi), kemudian dibuat seolah-olah menjadi nyata, bersatu dengan lingkungan sekitarnya adalah kemampuan Teknologi ini. Augmented reality menambahkan realita yang ada dan nyata di dunia kita 
dengan objek yang terangkat (augmented) [3]. Dalam pengembangan aplikasi berbasis augmented reality, dibutuhkan beberapa tools yang digunakan antara lain vuforia, unity, blender, make human dan lainnya. Ni Komang Oktari Permata Sari, et al.[6] menyatakan bahwa, software library untuk augmented reality yang menggunakan sumber yang konsisten mengenai computer vision yang fokus pada image recognition adalah vuforia. Unity menyediakan fitur pengembangan game dalam berbagai platform, yaitu Unity Web, Windows, Mac, Android, iOS, XBox, Playstation 3 dan Wii. Menurut Makehuman Team [9]. Make Human adalah software open source gratis yang diancang untuk prototype cepat manusia fotorealistic dan karakter(humanoid).

Untuk belajar mandiri gerakan silat, media yang ada hanya buku manual dan tidak ada alat peraga. Hal tersebut menyebabkan pesilat akan mengalami kesulitan dalam menghapal gerakan silat. Tujuan utama penelitian ini adalah memberikan media alternatif bagi orang yang ingin belajar pencak silat yaitu berupa buku panduan berbasis augmented reality (ARBook), media tersebut sebagai panduan untuk mempelajari gerakan dasar pencak silat bagi pemula dengan tingkatan dasar dengan teknologi augmented reality. Harapan dari penelitian ini dapat memudahkan pesilat itu sendiri dalam hal mengingat gerakan silat dan meningkatkan kemampuan skill agar lulus ketika ujian kenaikan tingkat. Selain itu untuk melestarikan salah satu aliran pencak silat asli Indonesia sebagai kebudayaan Indonesia. Berdasarkan dari latar belakang yang telah dipaparkan, peneliti mencoba mengembangkan sebuah media pembelajaran yaitu ARBook disertai dengan aplikasi Tata Gerak Dasar Silat menggunakan Augmented reality Unity Berbasis Android.

\section{STUDI LITERATUR}

Beberapa penelitian yang terkait Augmented reality berbasis android antara lain penelitian yang dilakukan oleh Muh. Arif Saputra [4]. Pada Penelitian ini adalah menampilkan sebuah citra tiga dimensi dari gerakan-gerakan shalat yang menyerupai aslinya, dengan cara melakukan scanning (pemindaian) pada gambar yang ada di buku melalui sebuah media yang disebut dengan Marker. Pada penelitian tersebut diharapkan bagi yang baru belajar gerakan dan bacaan shalat akan semakin antusias dan tertarik dengan tuntunan shalat yang sudah dilengkapi dengan teknologi Augmented reality. Hal tersebut karena pengguna bisa melihat gambaran nyata dari gerakan gerakan shalat yang menyerupai aslinya. Sedangkan Penelitian oleh Erwin Setiawan, et al.[5], penelitian ini bertujuan untuk pembelajaran tatacara gerakan wudhu menjadi lebih menarik dan menyenangkan menggunakan Augmented reality. Pada penelitian ini membahas teknik-teknik dasar pencak silat PPS Betako Merpati Putih meliputi Serangan Tangan dan Kaki dengan memanfaatkan teknologi Augmented reality yang bertujuan dapat membantu mengingat dan mengulas teknik untuk tingkatan dasar dan mematangkan teknik agar lebih baik, selain itu untuk upaya pelestarian kebudayaan pencak silat di bumi nusantara agar tetap terjaga kelestariannya.

\section{METODE PENELITIAN}

Setiap penelitian memiliki metode dalam mencapai tujuan tertentu. Pengembangan dari kerangka penelitian digambarkan dengan sub menu dari tahapan penelitian. Pada penelitan ini tahapan penelitian dapat dilihat pada Gambar 1.

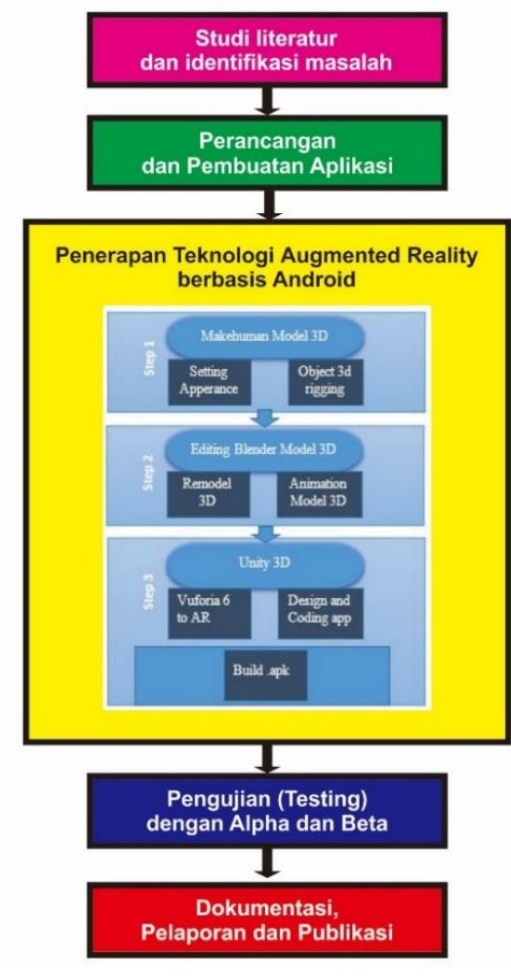

Gambar 1. Tahapan Penelitian

Adapun penjelasan dari gambar 1 adalah sebagai berikut:

\section{1) Studi Literatur dan Identifikasi Masalah}

Pada tahap ini dilakukan kajian literatur dari jurnal, skripsi, buku mengenai pembuatan aplikasi gerakan dasar pencak silat dengan animasi model 3D, yang menerapkan Augmented Reality berbasis Android. Mencari literatur tentang pencak silat antara lain pada [1], [2],[16] Selain itu beberapa penelitian yang berkaitan dengan Augmented Reality, antara lain pada penelitian [3], [4], [5], [6], [10], [11], [13], [14], [17]. Dalam pengembangan sistem dan pengujian dengan membaca beberapa literatur antara lain [7], [8], [15], [18] dan [12]. Dari studi literatur tersebut dan peninjauan ke lapangan, diidentifikasi permasalahan.

\section{2) Perancangan dan Pembuatan Aplikasi}

Tahapan ini dilakukan pemodelan atau desain yang terdiri dari desain konsep dan desain aplikasi yang dapat mempermudah dalam melakukan penelitian sehingga gambaran aplikasi yang akan dibuat jelas apa maksud dan tujuannya. Setelah itu akan dilakukan pembuatan program sesuai dengan gambaran aplikasi yang telah dibuat.

\section{3) Penerapan Teknologi Augmented Reality berbasis Android}

Pada tahap ini dilakukan penerapan teknologi Augmented 
Reality berbasis Android dengan memanfaatkan tool Vuforia pada Unity agar nantinya aplikasi yang dibuat dapat menampilkan animasi objek 3D.

\section{4) Pengujian dengan Alpha dan Beta}

Pada tahap ini nantinya akan dilakukan pegujian menggunakan Alpha dan Beta dengan kriteria yang telah ditentukan sebelumnya.

\section{5) Dokumentasi, Pelaporan dan Publikasi}

Pada tahap ini yang dilakukan adalah mengumpulkan semua hasil penelitian dan dibuatkan dalam bentuk laporan dan artikel ilmiah.

Berikut ini adalah bagan alir program yang di gunakan dalam merancang program dan menentukan bagaimana program berjalan dapat dilihat pada Gambar 2 .

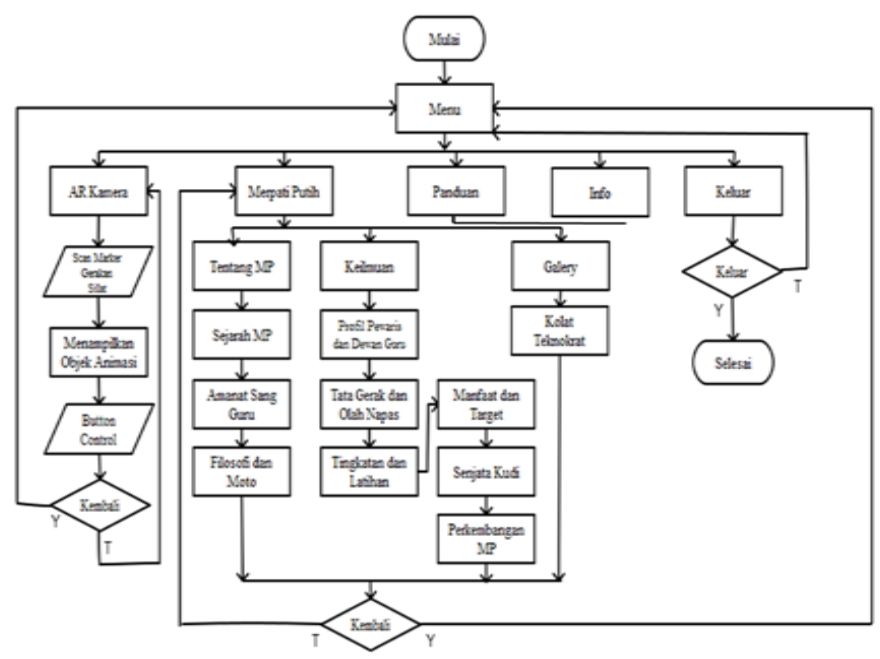

Gambar 2. Bagan Alir Program

Dari gambar 2 dijelaskan bahwa awal program dijalankan akan ada menu pilihan, antara lain; AR Kamera, Tentang Merpati Putih, Panduan, info dan Tombol exit. Tiap menu memiliki sub menu-sub menu.

\section{PEMBAHASAN}

Pada bagian menjelaskan dari hasil implementasi ke dalam pembuatan aplikasi.

\section{A. Implementasi}

Pada tahap ini adalah tahap penerapan kode program yang dimasukan dalam desain yang telah dirancang sebelumnya. Dari rancangan antar muka (user interface), dilanjutkan diimplementasikan. Hasil implementasi rancangan interface dapat dilihat sebagai berikut.

\section{1) Menu Utama}

Pada gambar 3 adalah tampilan dari menu utama, tampilan ini merupakan sebuah halaman yang berisi menu-menu yang nantinya akan dipilih oleh pengguna, halaman tersebut berisi AR Kamera, Merpati Putih, Pedoman, dan Info programmer.

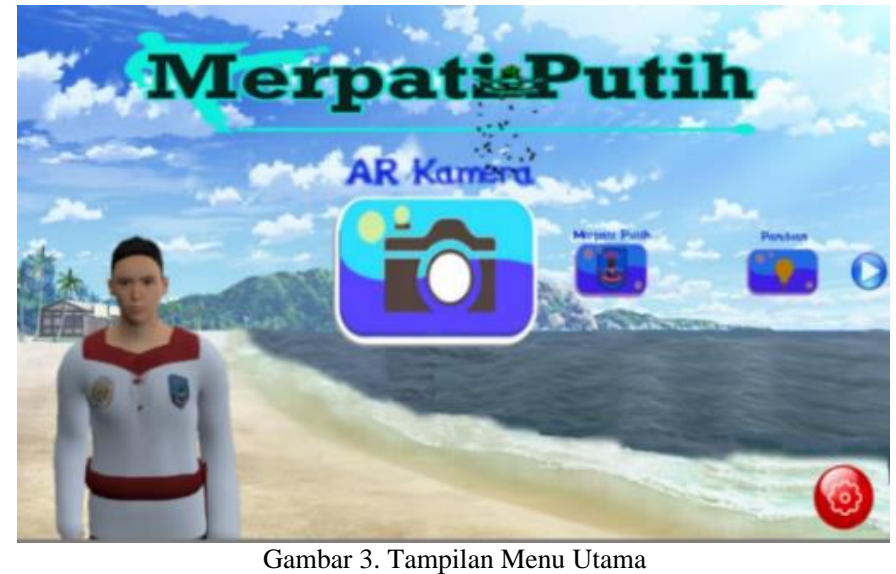

2) Tampilan AR Kamera

AR Kamera merupakan menu yang akan tampil ketika tombol menu AR kamera di klik, dan masuk loading scene dan apabila telah selesai masuk scene AR kamera. pada menu tersebut berisi tombol kontrol animasi gerak dasar silat merpati putih apabila telah scan marker, baik tombol play/pause, rotasi, zoom in/out, dan tombol hitungan per gerakan. Hasil implementasi menu AR Kamera dapat dilihat pada gambar 4.

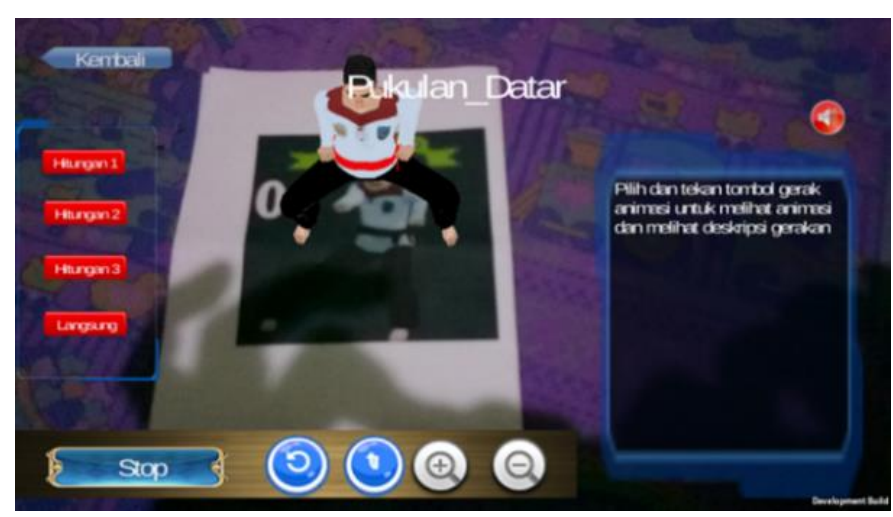

Gambar 4. Tampilan AR Kamera

\section{3) Tampilan Halaman Merpati Putih}

Menu Merpati Putih adalah tampilan menu yang berguna untuk melihat materi teori dari PPS Betako Merpati Putih, meliputi sejarah, amanat, filosofi dan motto, serta terdapat tombol back, next, kembali, dan scroll materi. Hasil implementasi Menu Merpati Putih dapat dilihat pada gambar 5.

\section{4) Menu Keilmuan}

Menu Keilmuan merupakan menu lanjutan dari menu Merpati Putih. Pada menu tersebut berisi materi seputar keilmuan Merpati Putih, sang pewaris, olah napas dan gerak, senjata khas, perkembangan, dan juga terdapat tombol back. Hasil implementasi menu Keilmuan dapat dilihat pada gambar 6. 


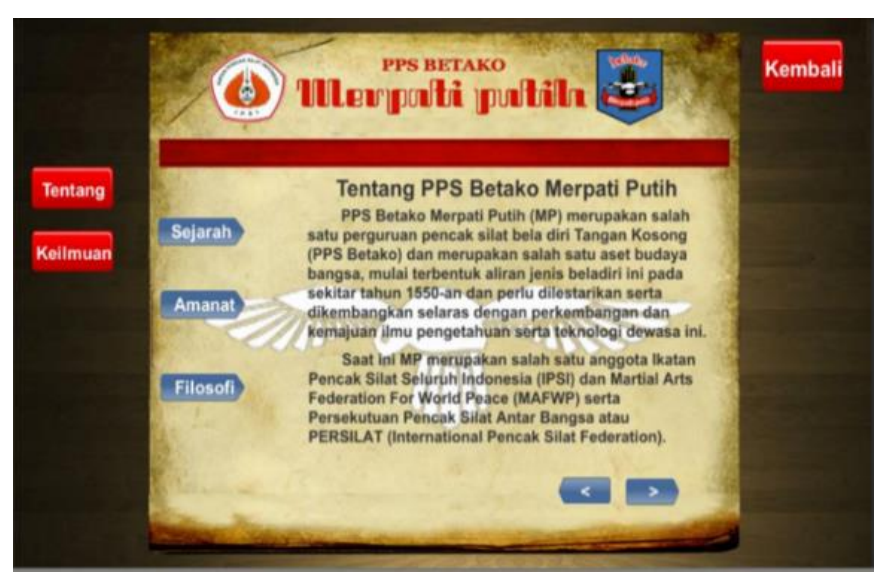

Gambar 5 Tampilan Menu Merpati Putih

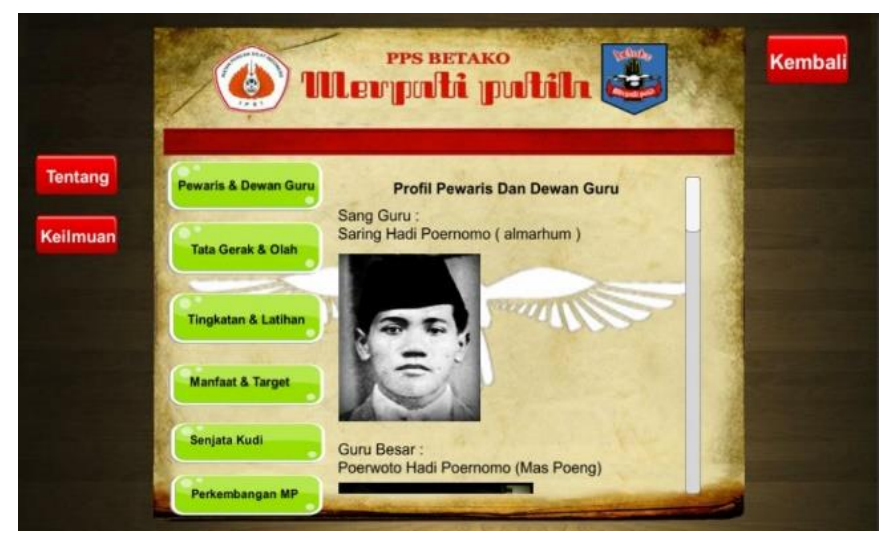

Gambar 6. Tampilan Menu Keilmuan

\section{5) Buku Panduan Gerakan silat berbasis Augmented Reality}

Pada gambar 7 dan 8 berikut adalah bentuk dari ARBook yang dijadikan media pembelajaran gerakan Pencak Silat.

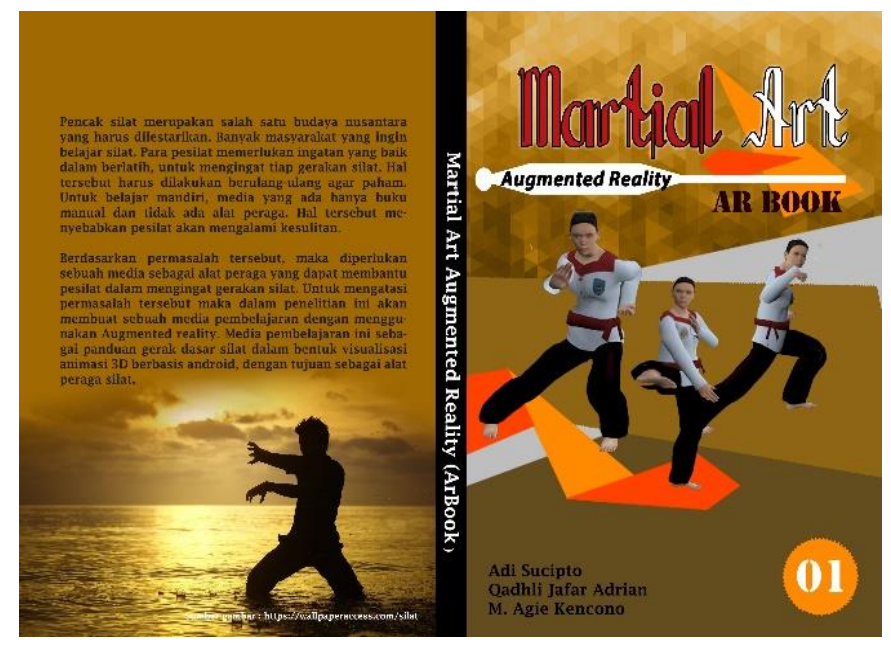

Gambar 7. Sampul ARBook Pencak Silat
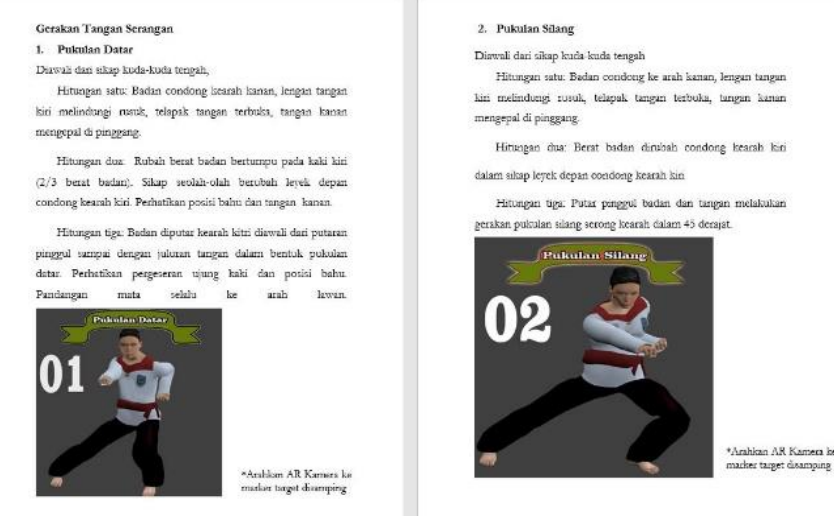

Gambar 8. Contoh isi ARBook Pencak Silat berisi marker

\section{B. Pengujian}

\section{1) Pengujian Alpha Aplikasi}

Pengujian Aplha Aplikasi Gerak Dasar Silat AR 3D dilakukan menggunakan Black box yang akan diuji berdasarkan fungsionalitas sistem yang berjalan pada aplikasi. Pengujian ini ditujukan ke 5 responden yang terdiri dari pelatih/asisten pelatih silat Merpati Putih untuk mencari informasi mengenai kesesuaian fungsi aplikasi dan gerakan silat. Kemudian selanjutnya diujikan juga kepada responden yang paham tentang Augmented Reality. Berikut hasil tabel pengujian Alpha Aplikasi Gerak Dasar Silat AR 3D.

TABLE I. UJi MENU UTAMA

\begin{tabular}{|c|c|c|c|}
\hline \multicolumn{4}{|c|}{ Spesifikasi } \\
\hline No & Masukan & Hasil Diharapkan & Hasil Pengujian \\
\hline 1 & $\begin{array}{c}\text { Klik Tombol AR } \\
\text { Kamera }\end{array}$ & $\begin{array}{c}\text { Menampilkan dan } \\
\text { membuka tampilan AR } \\
\text { Kamera }\end{array}$ & Layak \\
\hline 2 & $\begin{array}{l}\text { Klik Tombol } \\
\text { Merah Putih }\end{array}$ & $\begin{array}{c}\text { Menampilkan dan } \\
\text { membuka materi seputar } \\
\text { merpati putih }\end{array}$ & Layak \\
\hline 3 & $\begin{array}{c}\text { Klik Tombol } \\
\text { Panduan Aplikasi }\end{array}$ & $\begin{array}{c}\text { Menampilkan dan } \\
\text { membuka tata } \\
\text { penggunaan aplikasi }\end{array}$ & Layak \\
\hline 4 & $\begin{array}{l}\text { Kli Tombol Info } \\
\text { Programer }\end{array}$ & $\begin{array}{l}\text { Menampilkan dan } \\
\text { membuka halaman } \\
\text { pengembang }\end{array}$ & Layak \\
\hline 5 & $\begin{array}{c}\text { Klik Tombol } \\
\text { Pengaturan Suara }\end{array}$ & $\begin{array}{c}\text { Menampilkan dan } \\
\text { membuka pengaturan } \\
\text { suara }\end{array}$ & Layak \\
\hline 6 & $\begin{array}{c}\text { Klik Tombl } \\
\text { Keluar }\end{array}$ & Keluar Aplikasi & Layak \\
\hline
\end{tabular}

TABLE II. UJI AR KAMERA

\begin{tabular}{|l|c|c|c|}
\hline \multicolumn{4}{|c|}{ Spesifikasi } \\
\hline No & Masukan & Hasil Diharapkan & Hasil Pengujian \\
\hline 1 & $\begin{array}{c}\text { Klik Tombol } \\
\text { Play/Resume }\end{array}$ & $\begin{array}{c}\text { Memainkan } \\
\text { animasi/memberhentikan } \\
\text { animasi gerakan silat }\end{array}$ & Layak \\
\hline 2 & $\begin{array}{c}\text { Klik Tombol } \\
\text { Rotasi } \\
\text { Horizontal }\end{array}$ & $\begin{array}{c}\text { Memutar Objek Secara } \\
\text { Horizontal }\end{array}$ & Layak \\
\hline 3 & $\begin{array}{c}\text { Klik Tombol } \\
\text { Rotasi Vertikal }\end{array}$ & $\begin{array}{c}\text { Memutar Objek Secara } \\
\text { Vertikal }\end{array}$ & Layak \\
\hline
\end{tabular}




\begin{tabular}{|l|c|c|c|}
\hline \multicolumn{4}{|c|}{ Spesifikasi } \\
\hline No & Masukan & Hasil Diharapkan & Hasil Pengujian \\
\hline 4 & $\begin{array}{c}\text { Klik Tombol } \\
\text { ZoomIn }\end{array}$ & Memperbesar Objek & Layak \\
\hline 5 & $\begin{array}{c}\text { Klik Tombol } \\
\text { ZoomOut }\end{array}$ & Memperkecil Objek & Layak \\
\hline 6 & $\begin{array}{c}\text { Klik Tombl } \\
\text { Hitungan Gerak }\end{array}$ & $\begin{array}{c}\text { Menggerakan Objek sesuai } \\
\text { hitungan animasi }\end{array}$ & Layak \\
\hline 7 & $\begin{array}{c}\text { Klik Tombol } \\
\text { Kembali }\end{array}$ & $\begin{array}{c}\text { Kembali ke menu utama } \\
\text { Layak }\end{array}$ \\
\hline 8 & Tracking Image & $\begin{array}{c}\text { Kamera menampilkan } \\
\text { Image Target }\end{array}$ & Layak \\
\hline
\end{tabular}

TABLE III. UJI TRACKING IMAGE TARGET

\begin{tabular}{|l|c|c|c|}
\hline \multicolumn{4}{|c|}{ Spesifikasi } \\
\hline No & Masukan & Hasil Diharapkan & $\begin{array}{c}\text { Hasil } \\
\text { Pengujian }\end{array}$ \\
\hline 1 & Gambar Marker 01 & $\begin{array}{c}\text { Menampilkan Objek 3D } \\
\text { animasi pukulan datar }\end{array}$ & Layak \\
\hline 2 & Gambar Marker 02 & $\begin{array}{c}\text { Menampilkan Objek 3D } \\
\text { animasi pukulan silang }\end{array}$ & Layak \\
\hline 3 & Gambar Marker 03 & $\begin{array}{c}\text { Menampilkan Objek 3D } \\
\text { animasi sodLayakan } \\
\text { datar }\end{array}$ & Layak \\
\hline 4 & Gambar Marker 04 & $\begin{array}{c}\text { Menampilkan Objek 3D } \\
\text { animasi sodLayakan } \\
\text { silang }\end{array}$ & Layak \\
\hline 5 & Gambar Marker 05 & $\begin{array}{c}\text { Menampilkan Objek 3D } \\
\text { animasi sodLayakan atas }\end{array}$ & Layak \\
\hline 6 & Gambar Marker 06 & $\begin{array}{c}\text { Menampilkan Objek 3D } \\
\text { animasi sodLayakan } \\
\text { melingkar }\end{array}$ & Layak \\
\hline 7 & Gambar Marker 07 & $\begin{array}{c}\text { Menampilkan Objek 3D } \\
\text { animasi tebasan datar }\end{array}$ & Layak \\
\hline 8 & Gambar Marker 08 & $\begin{array}{c}\text { Menampilkan Objek 3D } \\
\text { animasi tebangan datar }\end{array}$ & Layak \\
\hline 9 & Gambar Marker 09 & $\begin{array}{c}\text { Menampilkan Objek 3D } \\
\text { animasi tebangan bawah }\end{array}$ & Layak \\
\hline 10 & Gambar Marker 10 & $\begin{array}{c}\text { Menampilkan Objek 3D } \\
\text { animasi ujung siku datar }\end{array}$ & Layak \\
\hline 11 & Gambar Marker 11 & $\begin{array}{c}\text { Menampilkan Objek 3D } \\
\text { animasi totLayakan }\end{array}$ & Layak \\
\hline 12 & Gambar Marker 12 & $\begin{array}{c}\text { Menampilkan Objek 3D } \\
\text { animasi tendangan datar }\end{array}$ & Layak \\
\hline 13 & Gambar Marker 13 & $\begin{array}{c}\text { Menampilkan Objek 3D } \\
\text { animasi tendangan } \\
\text { samping }\end{array}$ & Layak \\
\hline 14 & Gambar Marker 14 & $\begin{array}{c}\text { Menampilkan Objek 3D } \\
\text { animasi tendanga sabit }\end{array}$ & Layak \\
\hline 15 & Gambar Marker 15 & $\begin{array}{c}\text { Menampilkan Objek 3D } \\
\text { animasi tendangan } \\
\text { belakang }\end{array}$ & Layak \\
\hline 16 & Gambar Marker 16 & $\begin{array}{c}\text { Menampilkan Objek 3D } \\
\text { animasi pengkalan }\end{array}$ & Layak \\
\hline
\end{tabular}

Berdasarkan pengujian alpha yang dilakukan dengan black box testing di dapatkan hasil aplikasi yang sesuai dengan fungsional yang diharapkan pengguna, dengan hasil $100 \%$ semua fungsi dapat di jalankan sesuai seharusnya tanpa terkecuali.

\section{2) Pengujian Beta Aplikasi}

Pengujian Beta Aplikasi Gerak Silat AR 3D dan ARBook dilakukan menggunakan Quesioner yang akan diuji berdasarkan dari sudut persepsi pengunaan, kemudahan, Konten animasi, dan ketertarikan menggunakan aplikasi.
Pengujian beta diujikan kepada 20 responden yaitu siswa belajar. Tujuan dari pengujian ini adalah mencari informasi mengenai manfaat dari aplikasi ini dalam mempelajari silat. Untuk memperoleh persentase dari masing-masing jawaban dapat menggunakan rumus:

$$
Y=\frac{\text { TS }}{\text { Skor Ideal }} \times 100 \%
$$

Keterangan :

$\mathrm{Y}=$ Nilai presentase.

$\mathrm{TS}=$ Total skor responder $=\Sigma$ bobot $\mathrm{x}$ frekuensi. Skor ideal $=$ Bobot maksimal $\mathrm{x}$ jumlah responden

TABLE IV. KRITERIA PENGUJiAN

\begin{tabular}{|l|l|c|}
\hline \multicolumn{2}{|c|}{ Variabel Pengujian } \\
\hline No & \multicolumn{1}{|c|}{ Aspek yang dinilai } & Hasil $\mathbf{U j i}$ \\
\hline 1 & Kegunaan dan Maanfaat Aplikasi & $86 \%$ \\
\hline 2 & $\begin{array}{l}\text { Ketertarikan Menggunakan } \\
\text { Aplikasi }\end{array}$ & $79 \%$ \\
\hline 3 & Pengoperasian Aplikasi & $87 \%$ \\
\hline 4 & Konten Animasi & $84 \%$ \\
\hline
\end{tabular}

Berdasarkan nilai yang ada di tabel IV, didapatkan nilai rata-rata yaitu $84 \%$. Dalam penelitian ini skala pengukuran yang digunakan adalah skala Likert. Menurut penelitian [18], Untuk mengukur sikap pendapat dan persepsi seseorang/sekelompLayak orang tentang fenomena sosial menggunakan Skala Likert. Jawaban setiap item instrumen yang menggunakan skala Likert mempunyai gradasi dari sangat positif sampai sangat negatif.

TABLE V. KATEGORI PENILAIAN

\begin{tabular}{|l|l|c|}
\hline \multicolumn{3}{|c|}{ Variabel Pengujian } \\
\hline No & Presentase & Interpretasi \\
\hline 1 & $0 \%-20 \%$ & Sangat Tidak Layak \\
\hline 2 & $21 \%-40 \%$ & Tidak Layak \\
\hline 3 & $41 \%-60 \%$ & Cukup Layak \\
\hline 4 & $61 \%-80 \%$ & Layak \\
\hline 5 & $81 \%-100 \%$ & Sangat Layak \\
\hline
\end{tabular}

Berdasarkan nilai rata-rata hasil uji yang didapat yaitu 84 $\%$. Berdasarkan melihat tabel $\mathrm{V}$, maka dapat disimpulkan nilai $84 \%$ termasuk dalam kategori "Sangat Layak". Secara garis besar pengujian Alfa dan Beta menunjukkan aplikasi ini dinilai sangat layak dan dapat digunakan.

\section{PENUTUP}

Berdasarkan uraian yang telah dijelaskan di tahap-tahap sebelumnya, didapatkan kesimpulan sebagai berikut aplikasi Tata Gerak Pencak Silat khusunya PPS Betako Merpati Putih AR 3D dibangun dengan menggunakan bagan alir atau flowchart. Adapun pengembang program menggunakan IDE Unity yang merupakan aplikasi untuk pemrograman baik desktop maupun mobile yang support 3d objek, yang menggunakan Vuforia sebagai asset plugin untuk dapat membuat aplikasi augmented reality dan teknik pemodelan objek 3D manusia menggunakan aplikasi Makehuman dan menggunakan Blender sebagai editor dan software desain 3D 
modeling. Dasar-dasar gerakan silat dalam bentuk 3D disertai penjelasan adalah isi dari Aplikasi Tata gerak Silat AR 3D yang dibuat. Pengguna memperoleh informasi dalam bentuk visualisasi 3D dan dapat berinteraksi dengan gerakan silat 3D yang ada dalam aplikasi tersebut. Dalam penggunaan aplikasi, untuk menampilkan bentuk animasi 3D menggunakan marker yang ada di dalam ARBook. ARBook tidak diperjual belikankan, dan hanya sarana pembelajaran saja.

Berdasarkan hasil pengujian Arbook dan Aplikasi Tata Gerak Pencak Silat PPS Betako Merpati Putih AR 3D. Berdasarkan hasil pengujian alpha dengan menggunakan black box. Maka dari data tersebut dapat diketahui bahwa aplikasi gerak pencak silat 3D AR berjalan dan sesuai dengan fungsionalitas yang ditetapkan termasuk dalam kategori layak. Sedangkan pada pengujian Beta yang menggunakan metode penerimaan, $86 \%$ responden setuju bahwa Aplikasi Gerak Silat AR 3D memiliki kegunaan atau bermanfaat, kemudian $87 \%$ responden setuju bahwa mudah digunakan, selanjutnya $84 \%$ responden setuju sudah sesuai konten animasi yang disajikan, dan 79\% responden tertarik menggunakan Aplikasi Gerak Silat AR 3D. Secara garis besar pengujian Alfa dan Beta menunjukkan aplikasi ini dinilai sangat layak dan dapat digunakan.

Adapun saran untuk penelitian selanjutnya yang terkait dengan AR Pencak Silat ini adalah perlu pengembangan lebih lanjut, mengingat aplikasi ini hanya untuk gerakan dasar dalam silat. Penelitian selanjutnya diharapkan lebih dikembangkan untuk gerakan silat tingkat lanjut. Dalam pengujian bisa digunakan dengan metode lain. Saran selanjutnya adalah penelitian bisa dikembangkan dengan menggunakan multi marker atau dengan media yang lain.

\section{REFERENCES}

[1] Kriswanto, E. S., Pencak Silat. I. Yogyakarta: Pustakabarupress. 2015.

[2] Nugroho, N. B. and Tri, S. A. P. 2019. Tersedia:www.ppsbetakomerpatiputih.com.
[3] Anugrah, S. and Fernando, E. "Penerapan Augmented reality Sebagai Media Pengenalan Tuntunan Sholat Di Madrasah Ibtidaiah Nurul Hidayah Berbasis Android". PROCESSOR.2017.

[4] Saputra. M. A. "Aplikasi Tuntunan Shalat Menggunakan Augmented reality Berbasis Android”.E-Proceeding Of Applied Science. 2015.

[5] Setiawan, E., Syaripudin, U., Gerhana, Y. A. Implementasi Teknologi Augmented reality Pada Buku Panduan Wudhu Berbasis Mobile Android. JOIN.Volume I No. 1, 2016. 2016.

[6] Sari, N. K. O., Crisnapati. P. N., Kesiman. M. W. A., Sunarya I. M. G. "Pengembangan Aplikasi Augmented Reality BoLayak Pengenalan Tata Letak Bangunan Pura Goa Lawah Dan Pura Goa Gaja”, Jptk Undiksha. 2014.

[7] Lintrami, T, Unity Game Development Essentials. Packt Publishing. 2018.

[8] Enterprise, J. Blender Untuk Pemula. Jakarta: Elek Media Komputindo. 2016.

[9] Makehuman Team. Tersedia: http://www.makehumancommunity.org/. 2016

[10] Arifitama, B. Panduan Mudah Membuat Augmented reality. Yogyakarta: Penerbit Andi. 2017.

[11] Romadhon. E. N., Anra. H., Pratiwi. H. S. "Penerapan Augmented reality Berbasis Android Sebagai Media Pembelajaran Sel Penyusun Jaringan Pada Sistem Gerak Dalam Mata Pelajaran Biologi”, JUSTIN. 2017.

[12] Sugiyono. Metode Penelitian Kuantitatif, Kualitatif, dan $R \& D-M P K K$. Bandung: ALFABETA. 2019.

[13] Suharso, A. Muhaimin, M. " Media Belajar Kerangka Manusia 3D Berbasis MagicboLayak Augmented Reality (AR) (Studi Kasus SMPN 1 Kota Baru)", UNSIKA Syntax Jurnal Informatika Vol. 5 No. 1. 2016.

[14] Pamoedji. A. K., Maryuni, Sanjaya. R. (2017) Mudah Membuat Game Augmented reality dan Virtual Reality Dengan Unity 3D. Jakarta : Elek Media Komputindo.

[15] Pressman. R. S. Rekayasa Perangkat Lunak - Buku Satu (Edisi 7) . Yogyakarta: Penerbit Andi. 2012.

[16] Utama, R. Y. Implementasi Web3d Webgl Pada Gerakan Dasar Silat Pps Betako Merpati Putih Berbasis Android. 2017.

[17] Harahap, A., Sucipto, A., Jupriyadi. "Pemanfaatan Augmented reality (Ar) Pada Media Pembelajaran Pengenalan Komponen Elektronika Berbasis Android". Jurnal Ilmiah Infrastruktur Teknologi Informasi (JIITI),Vol. 1(1) p. 20. 2020.

[18] Guritno, Suryo, Sudaryono, \& Rahardja, Untung. (2011). Theory and Application of IT Research: Metodologi Penelitian Teknologi Informasi. Yogyakarta: Andi. 